\title{
Abstract \\ Profile of automobile related accidents encountered at District General Hospital Gampaha
}

Bandara $\mathrm{KDR}^{1 *}$, Thilakarathna GHIN ${ }^{2}$, Modaragama SDMP ${ }^{1}$, Jayawardana MAC ${ }^{2}$, Rathnayake $\mathrm{HACK}^{2}$, Ediriweera $\mathrm{D}^{3}$

${ }^{1}$ North Colombo Teaching Hospital Ragama

${ }^{2}$ DGH Gampaha

${ }^{3}$ Faculty of Medicine, University of Kelaniya, Sri Lanka

\begin{abstract}
\section{Background}

Automobile related injuries and deaths are a major problem in Sri Lanka. This study was conducted to describe the nature of automobile related accidents encountered at District General Hospital (DGH) Gampaha.

Methods

This is a cross sectional study done at the Out Patient Department of the DGH, Gampaha. All the patients coming with automobile related accidents on randomly selected days were studied. Data were analyzed and presented in cross tabulations and percentages.

Results

Of 448 automobile related accidents, $71 \%$ involved males. Majority of patients (41\%) belonged to the age group 20 to 40 years and most of the accidents took place between $4 \mathrm{pm}$ to $8 \mathrm{pm} \mathrm{(27 \% )}$ and 6 am to $10 \mathrm{am}(22 \%)$. Fifty percent of the accidents were motorbikes related and another $12 \%$ were three wheeler related. Fifty percent of the drivers and riders were injured and there were 23\% passenger and $22 \%$ pedestrian victims. Eleven percent of motorcyclist did not wear helmets and $12 \%$ of the patients were under the influence of alcohol. Ninety two percent of the patients did not receive first aid treatment and $70 \%$ of patients were transferred to hospital by three wheelers. Nineteen percent presented with loss of consciousness, $16 \%$ had fractures and $5 \%$ had internal injuries. Twenty nine percent of patients were discharged from Primary care unit, 58\% admitted to ward, 5\% transferred to specialized care units and $8 \%$ left the hospital.

\section{Conclusions}

High risk groups include 20-40 years, males, and motor cyclists with peak incidence during 6-10 am and 4-8 pm. This study highlighted the inadequacy of first aid treatment and requirement of proper transportation of victims.
\end{abstract}

Key words: Automobile; Accidents; Sri Lanka

Copyright: $\odot 2015$ Bandara KDR et al. This is an open access article distributed under the Creative Commons Attribution License, which permits unrestricted use, distribution, and reproduction in any medium, provided the original work is properly cited.

* Correspondence : rupika2011@gmail.com

Cite this abstract as: Bandara KDR, Thilakarathna GHIN, Modaragama SDMP, Jayawardana MAC, Rathnayake HACK, Ediriweera D. Profile of automobile related accidents encountered at District General Hospital Gampaha. Anuradhapura Medical Journal 2015;9 (2Supp):S34.

DOI: http://dx.doi.org/10.4038/amj.v9i2Supp.7583 
